\title{
A Science of Evil: An Exploration into Terror Management Theory and a Psychoanalytic Theory of Religious Extremism
}

\author{
Sayeed Devraj-Kizuk \\ Department of Psychology, University of Alberta
}

On September 11th, 2001, the United States was profoundly shaken when they were the victim of a tragic terrorist attack, in which 19 hijackers crashed two commercial airliner planes into New York's most treasured symbol of American prosperity, the towering world trade centres. Another plane hit the pentagon, bringing the total cost in human lives to approximately 3000 civilians. This event rocketed the Islamic terrorist organization Al Qaída into infamy, and has caused countless people to question how people could carry out these actions that were starting to dominate world news. Al Qaída is not a structured organization of terrorists. There is no base of operations or capitol for Al Qaída, no cultural obligation to be a part of the extremism, nor can people be born into Al Qaída, family obligations notwithstanding. People willingly join the extremists according to their own beliefs and conduct their operations in isolated small groups, without much contact with the leaders of the cause (The 9/11 commission, 2004). How could people willingly join something that causes so much destruction and pain? Even more confusing, how could people willingly die for this cause? Intentional suicide is a very different thing from joining a war with the knowledge that you may die in the fight. The idea of an individual deliberately choosing to end their own life, to accept the terror of death, in service to their cause is a shocking and troubling one, and it goes against everything that is intuitive about the behaviour of life-loving human beings. In this paper, I will attempt to describe the history and central themes of modern psychoanalytic theory, and in doing so, provide some insight into how the ideas of Terror management theory can explain how individuals can be capable of such extreme and perverse actions.

\section{INTRO TO TMT: THE QUEST FOR KNOWLEDGE}

Man is an inquisitive animal. For as long as we have been able to consider intelligently the world around us, we have been asking questions. The earliest records of religious behaviour date to at least the Upper Paleolithic era, or Late Stone Age, approximately 10-40 thousand years ago (Rossano, 2006). At the very birth of our species we began to question the nature of our place on this earth and the meaning of our existence. Mankind's quest for philosophical enlightenment begins with Socrates around 400 B.C.E. Socrates was a questioner. He sought knowledge through analysis of others, rather than postulating his own personal viewpoints. He would seek to understand courage, for example, by continually interrogating courageous men until he found a contradiction (Internet Encyclopedia of Philosophy, 2010). In this way, he can indeed be regarded as the first psychoanalyst. The history of philosophy, from this point on, continually builds on itself; the Greeks, the Christian philosophers of the medieval period, and the scholars of the Renaissance, all drew upon those that came before them, and all were influenced by Socrates' psychoanalytic questioning. Eventually, in the late nineteenth century, philosophy became incorporated into science in the work of an extremely influential German in the field of psychology named Sigmund Freud (Latham, n.d.; Becker, 1973) Figure 1 charts a few milestones in the understanding of the self.

Freud was the creator of psychoanalysis, a technique for understanding the structure of the mind based on logical deduction of the unconscious pressures and stresses on the psyche. Since the theory is based on logic and clinical observation rather than experiment, psychoanalysis has an element of the philosophical, which is clear in the parallels between Freud and Nietzsche (Latham, n.d.). This process produced theories that greatly improved comprehension of the human psyche and in recent years has allowed psychologists to study the mind through scientific experimentation. Although Freud himself believed that most of the behaviours that can be observed in human beings are due to repressed sexual and aggressive urges and instincts, this hypothesis has become increasingly less satisfactory to newer generations of researchers. Freud's train of thought, however, was not wrong, it was simply not going deep

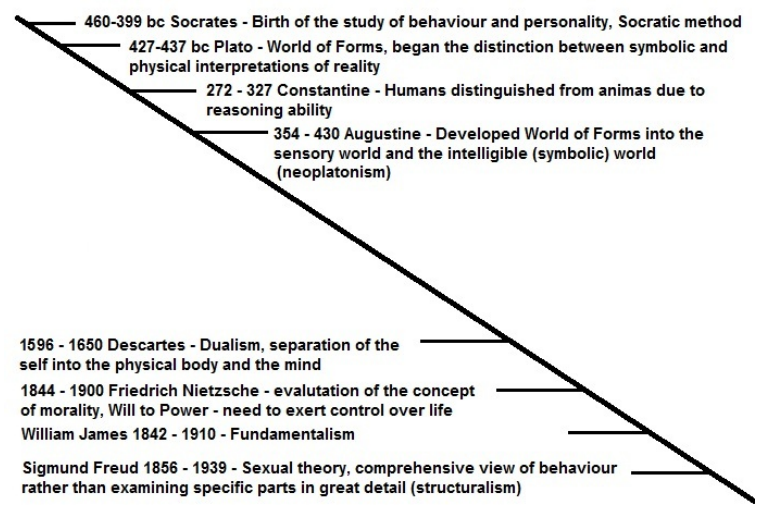

FIG. 1. A timeline of the understanding of the self. 
enough. Sexual and aggressive instincts undeniably exist, however they aren't convincing as the primary, intrinsic motivators for behaviour. A deeper, more fundamental instinct was needed, namely, the instinct to survive. Through the ingenious insights of psychoanalysts such as Jung, Adler, and Rank, and as clarified through the work of cultural anthropologist Ernest Becker (1973), a new theory has begun to emerge, one that places fear of death as the primary motivating factor, and has been named terror management theory.

Psychology, like all of science, has been building upon itself since the emergence of empirical investigation. In the study of the universal unconscious factors that influence human behaviour, through humanity's insistence to question the nature of our existence, two and a half millennia of thought have developed this one theory. The theory shows all-inclusive comprehension of the human condition, and can be used to understand and predict a myriad of different complex behaviours. Unlike its predecessors, it is supported by scientific experiments, which have profound implications for how we should proceed in the field of social psychology. It is the science of all that we are, of the entire human experience. terror management theory has the capability to accomplish at long last the fundamental goals of psychoanalysis. It provides insight into how to live happily, and provides an explanation for all of humanity's capacity for good and for evil.

\section{THE INTERNAL CONTRADICTION OF MAN}

\section{A. The Terror of Death}

Everything must die. From the smallest microbacterium to the highest towering redwoods, everything that lives is caught in a battle for survival, driven by the instinct to survive as long as possible, and produce some offspring to carry on the lineage. These are the basic animal instincts. But this is a fight that we all eventually lose. Every plant, animal, and microbe on this planet eventually runs out of time, and is reincorporated into the cycle of life. Even the sun itself will one day die, and in its catastrophic death-scene, vaporize the earth and the planets, ending this life cycle once and for all. The universe has a central theme of creation, and destruction.

Ernest Becker argues, in The Denial of Death (1973), that of all the living breathing things on this planet, only humanity has the misfortune of knowing that it is doomed. We have just as much of that animal instinct to survive as any other species, and what's more, we have the intelligence to rejoice in life, to understand how fantastic it really is to be alive, to see the beauty in the world, in ourselves, and in each other. To us, every day is a gift, every experience a wonder, every second spent alive an affirmation to the greatness of our kind. We are also able to visualize ourselves as separate, indi- vidual beings. Furthermore, we have the ability that no other species has to remove that sense of self from our present location in position and time. Through our infinite imagination, we can project ourselves onto the surface of the moon and look down at our own world, or we can shrink ourselves down and contemplate the structure of matter while sitting on the nucleus of an atom (p.26). We can travel back in time years to our childhoods, and project ourselves forward in time to our old age, or some distant future. Or to the day of our death. The same intelligence that allows us to fully appreciate life also forces us to acknowledge the inevitability of our biology: that we are impermanent, if superlative, beings on this planet, and that for all of the creativity and divinity of our minds, our uniqueness in all of nature, we still cannot escape the finitude of our bodies. It is utterly both inacceptable and inescapable for us to die. This is the eternal confliction within man's psyche. It is the cause of tremendous anxiety, that, if not dissipated in some way, would be so overwhelming that not a single one of us would be able to function, to do anything without cowering in fear of accidentally slipping and cracking our heads open like eggshells on the sidewalk. This is the terror of death that terror management theory postulates as the central driving force behind our actions, and all that we do in life is part of our desperate attempt to repress our fear of death, and to conquer it (Becker, 1973; Shen, 2006).

\section{B. A Symbolic Life}

If humanity has been burdened by its intelligence, thrown into an unwinnable struggle for life and be forced to see it as unwinnable, then at least it is given by that same intelligence the means, through complex psychological structures, to deal with this burden. In order to understand these structures fully, we must talk briefly about Humanity's paradoxical nature. The human being, according to Becker (1973) is a combination of two entities, half animal and half symbolic. The animal nature of humanity is simple and undeniable, we have instincts and urges, and our bodies require food and drink and air or they will expire. And most importantly, sooner or later, they will expire. The symbolic nature of humanity, what separates us from the rest of nature, is more complex, and has more profound implications. We have imagination, creativity, and individuality. We have an identity, a name, a history, and a future; non-concrete things that only have meaning in the minds and words of human beings. These traits are what allow us to shake off our fear of death, to deny the reality of our physical condition by living fully in the symbolic, endowing us victory over physical mortality through what Becker calls symbolic immortality.

As human beings grow and make their way through the world, they develop a unique set of values and beliefs, as well as a set of aspirations, hopes and dreams. 
Put simply, people generally figure out which things in the world are most important to them - their religion, art, work, lovers, family, country, a cause, or any combination of these ideals. Together, they come together to form a personal world-view, a mental picture of what is good and right in the world. terror management theory postulates that personal worldviews develop because they serve to shed the existential dilemma, and allow people to occupy their minds with goals that are actually attainable, and will result in some measure of symbolic immortality. (Becker, 1973, Shen, 2006) This makes those values no less meaningful or significant, it simply explains why people cling so tightly to their worldviews and ways of life, and why they are so devastated if their aspirations are not realised.

The success in realizing this personal worldview becomes tantamount to their success in conquering the anxiety of death, in a symbolic and personally meaningful way. Naturally, it should follow that people should feel more anxious and unstable the more the reality of their lives deviate from the ideal of their personal worldview, and people should feel more confident and happy the closer they are to fully realising that set of ideals. Indeed, what we know as self-esteem is defined in terror management theory as how successful a person is in realizing, in themselves, their personal worldview (Shen 2006).

\section{SCIENTIFIC SIGNIFICANCE}

While the theory certainly presents some interesting ideas, one must enquire on the scientific significance of these various and far-reaching claims. How can we be convinced that death is really the central anxiety, and not mere speculation? The science of functional psychology has reached a stage in which it is highly theoretical, formulated not from concrete experimental data, but from clinical observations and logical deduction. Experimental data in support of TMT has been widely conducted a propos of the theories, as proof and evidence. In a science such as this, the significance and truth of a theory can be evaluated by showing how allinclusive the theory is. Much like the difficulty faced by the physical sciences in describing the nature of the very small, we may not be able to directly observe these processes as they are happening, but if the theory encompasses and accurately predicts all behaviour that we can observe, then it can be taken as an accurate model of the subject in consideration. In the next few sections, I am going to show how multiple behavioural patterns that we see in our modern society are convincingly explained by terror management theory, and then use those explanations to examine the behaviour of some people which we might otherwise see as absolutely baffling.

\section{TRANSFERENCE}

Transference is a complicated but integral idea in the study of human behaviour. In order to overcome the fear of death, and the impotence associated with it, people will often make use of some type of meaningful object in order to project their feelings of insecurity onto someone or something. This can happen in many ways, and is an explanation for a variety of human behaviours.

\section{A. The Hero and Anti-hero}

Throughout the chronicles of history, we see time and again the emergence of heroic individuals. Wherever there is a great event in human history, a great war or great empire, or an influential cultural movement or revolution, there is an unusually powerful person in the centre, shaping the history of the world by their actions as though tied to the very fabric of fate. Examples of such heroes could be Alexander the Great, Winston Churchill, Vladimir Lenin, Martin Luther King Jr., the Prophet Mohammed, or Jesus Christ. According to TMT (Becker, 1973), heroism is transference of death-anxiety from a group of people onto a single relatively virtuous person, which has the effect of elevating their perceived virtuosity and importance.

Transference, Becker (1973) states, is ubiquitously agreed on by psychoanalysts as a problem with courage. When people are in a vulnerable position, and doubt their own abilities to achieve symbolic immortality, they choose another person to do it for them. They see the person, not for who he or she really is, but as the embodiment of all the characteristics that they wish they could embody in themselves. Those who see themselves as weak, and foolish, and impotent, will see the hero as infinitely strong and wise and powerful. They elevate the hero to a position where it would be impossible for him or her not to achieve symbolic immortality, to change the fate of the world. Followers achieve their own immortality through these great and powerful people, in a diminished way, by convincing themselves that they are part of some great cause championed by a great hero. This is why great people in history almost always are in command of, or worshipped by, huge numbers of people. Their greatness is not due, in most part, to their own inherent properties, but those imposed upon them by their followers.

This process also explains why people can do things that would normally be completely contrary to their personal worldview, such as murder, for their cause. People place their entire life-project, their only chance to evade the terror of death and find peace, in one individual, and in their associated cause. The cause begins to define the individual, to become a new personal worldview, with the hero as a focusing point, and the success of the cause becomes the success of the individual. This creates a moral dilemna for the individual. What happens 
when the beloved hero commands a peaceful person to destroy? The individual has committed himself or herself to the cause, and in effect abandoned his or her own personal worldview, his or her own individual quest for immortality as dictated by personal beliefs, values, and morals, and allowed it to be subjugated by a stronger defense, the hero/cause transference object. The individual will then commit the act because to defy the hero would be to lose that bid for immortality. However, this does not occur without some consequences for the individual. If the individual is completely immersed in the hero and the cause, he or she can no longer return to the original, personal worldview once the ideals of that worldview have been violated. Within the cause, the individual is a holy warrior, achieving his or her selfesteem by conforming to the wishes of the transference object, even if they contradict personal values. If the individual were to leave the group, he or she would be a pathetic and miserable failure in the terms of the old, personal worldview. The cause has become his or her new shield against the terror of death. It is close to impossible for a person to exchange a strong defense for a weaker one, even if he or she at some point realizes that the strong defense is fundamentally wrong, because that would mean facing the terror of death, braving the fear that defines a person at the very core, and accepting it as a part of life. If the essence of a person's life is an attempt to run away from the reality of death, how can anyone be expected to act in a way that will only bring them closer to this truth? (Becker, 1973).

As a final point on hero-based transference, Becker (1973) states that transference of the kind discussed above can occur positively, as in the hero, or negatively, as in the anti-hero. In this case, the process is exactly the same but with reversed emotions. The anti-hero is seen as the embodiment of everything that the person despises within his personal worldview, and is elevated to a level of ultimate evil rather than supreme virtuosity. The individual then finds his self-esteem in the quest to destroy the negative transference object. The individual will stop at nothing to realise that goal, and in doing so, earn his or her symbolic immortality by cleansing the Earth of some great evil. During this quest, individuals may have to resort to means that contradict their personal worldviews in order to proceed. After the quest is over, after the evil is destroyed or these people are forced to give up, they find it difficult to return to the old worldview for the same reason. The self-esteem gained from the personal worldview was tarnished by the act of pursuing the evil. This idea of negative transference can help explain why people will so self-destructively hold onto the past, as well as some obsessive behaviour. A couple archetypical examples of such cases could be police officers who become obsessed with a criminal they were unable to catch (Mikulenka, 2007), or soldiers that experience difficulty returning to their regular lives after a war (Helzer, 1987).

\section{B. The Failure of Transference}

Heroism is characterized by a group of people projecting their anxiety onto a single person. However, there's quite a variety of projections that we human beings are capable of. Two people can project their anxieties onto each other, which occurs during what we know as love. Sometimes, only one is projecting onto the other, which is characteristic of a platonic relationship, or in more extreme circumstances of obsession. People can project onto inanimate objects or meaningless rituals, as seen in fetishism, superstition, and other kinds of magical thinking. People can even project onto the products of their own minds, which gives the world our greatest artists, musicians, and authors. Indeed, anything that has contributed to the development of culture can be explained through the need of all human beings to distract their minds from the anxiety of death. All of these transference objects, however, are doomed to fail, because they all are based off other human beings or the products of human beings. This makes the objects unstable, and the process has the potential to cause deep anguish for the individual (Becker, 1973).

Becker (1973) argues that the fundamental flaw with human beings as transference objects is that in order for the object to be an effective distraction against the individual's imperfection and impermanence, he or she must elevate it to a divine status, or the transference has no weight. This entire psychological structure is thus weakened by the fact no person can ever be perfect or immortal. Inevitably, all individuals will be forced to see that some of the things that they despise are in some way present in that person. If one has deluded his or her hero, or beloved, to a state of immortal perfection, and one's own bid for immortality is dependent on the other's immortality, then what does it mean when one finds imperfection in his or her object of transference? The individual's own bid for immortality is of course diminished. When people become "disillusioned" in their love or hero, their self-esteem gradually drops along with their opinion of the transference object, and feelings of hurt and frustration towards the object are the result. Worse yet, if the object is ripped away, if the hero dies or abandons the cause, or if the beloved dies or leaves them, then the self-esteem gained from that relationship is brought crashing down. Of course, some objects are better choices than others, and it is perfectly possible to live your entire life, if you are lucky, entirely fulfilled by a finite transference object. However, it is these possibilities for failure that ultimately make transference onto persons intrinsically weak and unstable. Figure 2 shows an example of one of the stronger human transference objects in history.

This idea of the failures of transference provides insights into many behaviours of people in their social relationships. Why can people who were once passionate lovers show so much hatred towards each other? Why is domestic violence often associated with rela- 


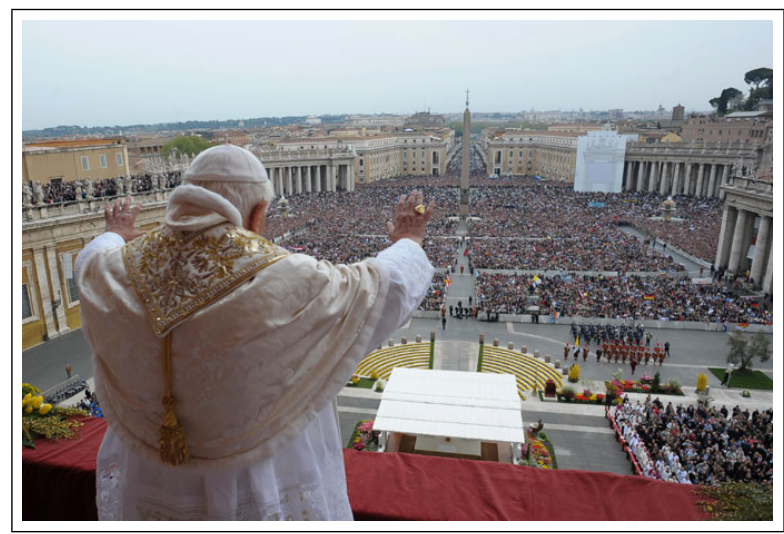

FIG. 2. The Pope is one of the strongest human transference objects in the world today. How can it be possible that so many people show such devotion to a person with whom they have had no personal interaction? (http://mediagallery.usatoday.com/Pope+Benedict+XVI)

tionships that those involved could not bear to leave? Why, througout history, were authoritarian leaders so often thrown from power and executed, only to be replaced by another who is rarely any improvement? Why are celebrities made the focus of a whole culture one day and demonized the next? These violent fluctuations in public opinion towards influential people can be convincingly explained by the fact that transference towards a person simply is not viable as a strong, lasting solution to the problem of death. People are only just that, people. No one can last as the image of divine perfection for another. It causes too much strain, puts too much weight on the shoulders of the hero or love object, and gives them an impossible role to fulfill. Eventually, individuals will lose faith in the immortality of the transference object, either indirectly, by rejection or disillusionment, or directly, by the actual loss of the person. They find themselves having forsaken their personal worldview to focus on another individual, yet the other is bringing more pain than happiness. They cannot succeed in this new immortality project, nor can they return to the old one, the original personal worldview. This is the eventual fate of any form of transference to another human being. In truth, there is only one entity in existence that can serve as a strong, viable transference object, the only thing that can forever act as an immortal, perfect being in the mind of the individual. This being, as Becker (1973) explains, is of course what we know in our culture as God.

\section{Religion}

The concept of religion is perhaps one of the most complex and interesting topics that one can study using the approach of psychoanalytic theory. Religion is a staple of all cultures across the world and has been around as a solution to the problem of death since the Stone Age (Rossano, 2006). An explanation for its remarkable prevalence is that as such a solution, it provides the most stable and most fulfilling answer that man has yet achieved. From a psychoanalytic standpoint, religion is simply transference, but one that uses a spiritual and all powerful, yet intangible, entity as the transference object. The presence of a deity takes the transference object from the physical realm and places it in the spiritual, or symbolic realm (Becker, 1973). The individual no longer has to elevate a physical being to a level of divine perfection in which to place his trust and faith, he instead relies directly on a pre-existing, allpowerful, all-knowledgeable, all virtuous being. This does not have any of the complications that arise from transference to persons. The individual cannot become disillusioned in the imperfection of God, because God by definition has no imperfection. Because God is always perfect, no fault can be due to God. If there is evil in the world, it is due to humanity, or to himself, but never to God. He cannot be abandoned by his transference object because God cannot die, or leave him, or be lost. God is always there, an eternal presence. Because God never interacts directly with the individual, God can never be blamed for his failures. Neither can He feel the pressure of being the source of happiness for the individual, and so reject him. It is obvious. If transference fails when we try to make imperfect beings perfect and immortal, then the difficulties vanish once a transference object is found that already contains these qualities. God is the only strong, viable transference object that a person can safely trust with his or her psychological security without the possibility of having it crushed, sooner or later, by the object's infallibility (Becker, 1973).

What God really is to humanity, is the very essence of the symbolic immortality that humanity wants so desperately. Human beings, in religion, create the finest of illusions to veil from themselves the reality of their death. It is similar to the illusion of the loved one or the hero, but assigned, not to a physical object which would weaken the illusion, but to the very idea that the individual is trying to achieve. In order to achieve symbolic immortality, humanity transfers their deathanxiety onto a being that represents the concept of symbolic immortality itself. We also give ourselves the added pleasure of making the fulfillment of this new personal worldview unbelievably easy to fulfill. Essentially, the only thing that must be done to be accepted into a religion, and to be a good follower of religion, is to believe in that religion. Humanity has created for itself a cultural worldview, wherein, simply believing in that worldview fulfills it, securely warding off the omnipresent terror of death. 


\section{A CASE STUDY: EXTREMIST THEORY AND THE PSYCHOLOGICAL MOTIVATIONS BEHIND AL QAÍDA}

In the past century, there is no lack of instances of perverse and inexplicable group human behavior. Nazism, Genocides in Rwanda and across Africa, and on a smaller scale the many examples of regular, moral people acting atrociously out of prejudice towards ethnicity or sexual orientation, all can attest to the propensity of considerable numbers of people to engage in objectively immoral lifestyles for prolonged periods of time. In order for a large group of people to live in a fashion that would normally be so far from their regular personal worldviews, there has to be opportunities for extremely effective cause/hero transference. For an extreme and perverse cause to take hold, there are multiple factors that can strongly contribute to the strength of the transference. These factors include:

1. An environment that contains strong and consistent death-reminders

2. A strong unifying motive that draws the people of the group together

\section{A charismatic and heroic individual}

4. An easily demonized and targeted scapegoat or Anti-hero

The first two factors deal with the environmental hardship that creates the need for the extremist cause to come about. This need for an escape must be strong enough that it pushes people into something they might not otherwise believe in. The second two factors deal with the appeal of the cause itself, which must be strong enough to pull people in when they are troubled by the environmental hardship. When both of these factor groups are strong, it creates a situation that forces the people into the extremist cause, because it is the easiest and often the only way available to them to achieve their symbolic immortality.

It is somewhat of a non-consequential observation that people most often react in extreme ways when they are confronted with extreme situations. Al Qaída was created in Afghanistan and has grown into an extremist movement throughout the Middle East (The 9/11 Commission, 2004). Many countries in this area have weak and disparate economies, extreme poverty, and are wartorn and dangerous. These types of environments cause extremely high levels of existential anxiety for the inhabitants because there is a constant reminder of death and the possibility of dying. In places like this, it is inescapable. The regular sight of malnutrition and sickness, the hidden explosives and remnants of wars long past, and the armed troops and warfare that is still being seen by many in these regions, all present the perception that death is everywhere. If human beings seek symbolic immortality through their personal passions as a reaction to anxiety about death, then it should follow that if death is more prevalent in an individual's mind, the result will be a heightening of anxiety and the need to escape death using some kind of immortality symbol. This is the idea of death-reminders or mortality salience. People living in stressful situations are reminded more acutely about their own death, and so they will go to more extreme measures for some way to transcend their fear and achieve their immortality.

The second aspect of an environment that provides the ideal substrate for extremism is a strong unifying factor that brings people together, and provides the emotion that the extremist cause draws on. In the Middle East, this has to do with Islamic, particularly Sunni political history. This is addressed in detail in the 9/11 Commission report, (2004) and I will give a very brief description. In the history of Islam, there was no separation of the church and the state. Muslim communities had governments that enforced law in accordance with Islam's teaching only, and the state was a completely religiously directed entity. This idea that the country's religion and politics are inseparable has been present since Islam's inception, and it retained a measure of that idea for many hundreds of years. Over time, the Muslim empire weakened, and became loosely represented by the Ottoman empire, which was slowly defeated by European powers, the remnants of which is now Turkey. In the following years, Europe and the Americas became more profitable and the Muslim world became generally poorer. The extremists view this trend as the defeat of Islamic nations by Judeo-Christian nations. In the modern world, some Islamic countries do not enforce religious obligations, and do not act as defenders of Islamic ideology as they once did. The extremists view this embracement of western practices as tantamount to Christian and Jewish influence destroying aspects of Islamic culture. This is the unifying concept that the extremist cause uses to foster a spirit of unity within $\mathrm{Al}$ Qaída, that the members of the cause are fighting to restore Muslim nations to their once former glory and to regain aspects of their culture that have been lost. In this way, the members of the cause are allowed to see themselves as champions of their world, fighting for a truly noble cause.

Now we move on to the idea of the hero and the anti-hero. The extremist cause in this case is one that is very strong because it combines aspects of religious and heroic transference. The member has strong, charismatic leaders, the most prominent being Osama Bin Laden, until his death in 2011. Osama Bin Laden was an extremely virtuous figure when seen from the extremist Islamic perspective. He was university educated, and spoke eloquently and fluently on religious scripture. His first efforts in Al Qaída, at which time the movement is generally thought to have begun, were in Afghanistan, where he used his considerable family fortune to train local militants to combat and free themselves from a brutal and oppressive Soviet occupation. Long before his involvement in any terrorist ac- 
tivity, many Arabs idolized Osama Bin Laden for his intellectualism, ambition to protect Muslim rights and freedoms, the position of power given to him by his fortune, and ultimately the successes that came from those qualities (The 9/11 Commission, 2004). However, there is a strong difference between him and the regular hero, because he is a spiritual leader of the cause. Osama Bin Laden does not direct all of Al Qaída like his own private army. Al Qaída is a disjointed group of extremists that idolize him and follow his teachings and instructions, but do not act directly out of submission to him. The real drive for their actions is the ultimate transference object, religion. The members are then selfdirected, acting in the style dictated by their hero but ultimately not to please the hero, but to please God. In this way, they have the strong appeal and love for the hero, who is divinity embodied. But, they also have the strength and stability of the religious cause. Indeed, almost all religions have a lineage of human representatives associated with their religion, be it the Pope, Imam, or divinely appointed royalty, because it strengthens the religious transference by giving it a more grounded, physical nature. The desire for extremist Muslims to follow the wishes of Osama Bin Laden is identical, in nature, for the desire for astute Catholics to adhere to the wishes of the Pope.

And finally, we come to the anti-hero. When the historical background is considered, the United States is clearly a strong candidate. If the extremist cause is fighting in opposition to the defeat of Islamic culture by western culture (Judeo-Christian world) and the unjust reduction of the Muslim empire to poverty while the western world has become wealthy and prosperous, then there is no greater example of western influence than the United States. The extremist cause is strongly religious in nature and the United States has become a non-religious state, at least from the perspective of the government. The American-dominated popular culture, media, and music of the west often promote promiscuity, rebellion, and self-promotion, the exact opposite of Islamic religious ideology. The United States has the reputation of being the most prosperous and wealthy western nation, and it is the most successful superpower that has grown out of the Judeo-Christian culture of colonial Western Europe. In addition, the United States supports Israel in their foreign policy, and had a strong military presence in the Middle East before the War on Terror. All of these factors made the United States an extremely tempting scapegoat. All of the problems of the Muslim World can be seen inversely reflected in this one country, and because the extremist cause is primarily a holy war, then it is no surprise that they call the United States the "Great Satan" (The 9/11 Commission, 2004).

Now that we have considered all these factors, we can see how the members of Al Qaída can perform such terrible actions, and even give their own lives willingly and knowingly, for their cause. They live in an extremely stressful environment, which burdens their minds with an unbearable amount of death related anxiety. This anxiety is manifested in religious devotion, and indeed a huge majority of the Middle East are strong believers in Islam (The Pew Forum on Religion \& Public Life, 2011). But for some in these situations simply having religion is not enough, and during the 1970's there rose a strong, reputable, and heroic figure who they could follow. This hero gave them a purpose, a way to achieve further symbolic immortality by being part of a great and noble cause that would shape the fate of the world. In addition to this, their cause was intricately engrained in their religion albeit twisted from its true values and so their transference object was the eternal God, and their self-esteem was bolstered on two levels, by service to their religion and service to their cause. If they began to see that the cause was in actuality acting against the principles of their religion, or they began to be asked to perform actions that they knew were not within Islam or their personal values, they could not turn back. They had pledged allegiance to the cause, and to leave it would be to sacrifice their symbolic immortality, and return to a life where they can only be branded as criminals. For those who still did believe, to die in service to the cause becomes desirable, because they cannot fail in their mission. If a suicide bomber dies with the belief that his act will bring his cause ever closer to its goals, and will strike a blow at the heart of the enemy, then by his act of death he is achieving his symbolic immortality, and so he is capable of dying without fear. Instead, he is guaranteed his immortality, because once he completes his act, he finishes his life-struggle in the highest possible state of death denial.

The people who compose Al Qaída are often depicted in the West as monsters, religious fanatics with no goals but to destroy those who do not believe what they believe. But to truly believe that view is ignorance. They are human beings, with thoughts and emotions, and have just as much capacity as the rest of us to feel love and happiness, anger and indignation, sorrow and guilt. They are put in a difficult situation and given an easy solution. This solution may cause pain for others, it's true, but that pain comes as the price of their own self-esteem and peace of mind. Without it, they run the risk of living a life that has no meaning, one that gives them no feeling of self-worth, and no hope for immortality. A life where their life could end at any moment and it would have meant nothing at all. It is too easy for us here in the western world to judge those whose behaviour would be inacceptable in our safe, comfortable, and supportive society, but allow yourself, for a moment, to imagine living in their circumstances. Can you honestly say you would act any differently? 


\section{EXPERIMENTAL EVIDENCE}

While Terror management theory is based on sound and extensive clinical work by some of the most renowned psychologists in the field (Becker, 1973), it cannot be taken as scientifically significant without being supported by specific experimental study. In past few decades, social psychologists such as Jeff Greenberg, Sheldon Solomon, Tom Pyszczynski , Jeff Schimel, and Joseph Hayes have been conducting lab research in support of terror management theory. Some of their experiments yield results that are convincing and indeed quite striking.

Two main hypotheses are focused on in TMT studies. The first has already been mentioned, that is the hypothesis of mortality salience, which dictates that if knowledge of mortality is made salient to a subject (if they are reminded of death) they will demonstrate stronger support for their cultural world-view and weaker support for an opposing worldview. Rosenblatt, Greenberg, Solomon, Pyszczynski, and Lyon (1989) asked judges whose occupation demands a strong sense of cultural values to recommend a bond for a prostitute, whose occupation infringes upon cultural values. The average bond recommended by the control was \$50. If mortality was made salient, however, the average bond recommended rose to $\$ 455$. This was repeated with students, and found that the same result occurs, however, even when mortality was made salient, an increased negative reaction towards prostitution was not observed if the student did not beforehand report a negative attitude towards prostitution. This suggests a direct relationship between mortality salience and cultural values. The study was also reversed for a hero who upholds cultural values (a woman who turns in a violent burglar in spite of possibility of harm to herself). The control recommended a reward of $\$ 1,112$. When mortality was made salient, the reward rose to $\$ 3,476$. Further research (Rosenblatt et al, 1990) showed that when mortality was made salient, subjects with a Christian religious background, when asked to form impressions of otherwise identical Christian and Jewish target persons, showed especially positive evaluations of the in-group member (Christian) and especially negative evaluations of the out-group member (Jew) when MS was induced. This research was further applied to attitudinally dissimilar persons, and persons who either praised or criticized the subject's cultural worldview, with supportive results.

These findings with Mortality Salience were used to study self-esteem (Greenberg et al., 1997). Subjects were first primed with either positive or neutral feedback on a personality test. The positive feedback served the purpose of bolstering the subject's self-esteem, and a selftest was administered to record this effect. The effects of MS were then tested. Subjects were given two essays, pro U.S. and anti U.S., and asked to rate the authors. In the control (neutral feedback) MS induced a large difference between the subject's opinion in the two authors.
$(\mathrm{M}=3.06$, higher statistics mean larger disparity) The control without MS showed relatively little difference $(\mathrm{M}=0.92)$. In the positive feedback group, however, both the control and MS showed the same difference in opinion as the neutral feedback control. ( $\mathrm{M}=0.89$, 0.90). Only the group that had induced MS and received neutral feedback showed especially positive and negative responses towards the authors that supported and criticized their culture, respectively. This suggests that increasing a subject's self-esteem has a buffering effect on mortality salience and death anxiety. This is important research in TMT, because it shows that if a subject has a high opinion of themselves, it removes the need for death suppressive constructs even after MS. This trend was replicated (Greenberg, 2008) using threatening videos and electric shock as the MS, and anxiety state tests and skin conductivity in order to measure anxiety.

Mortality salience has also shown subjects to be more supportive of charismatic leaders and less supportive of practical leaders (Arndt et al., 2004), more distasteful of sex unless reminded of romantic love first more fair, and an increased striving for uniqueness or similarity to others, depending on which was threatened (Greenberg, 2008).

The second hypothesis is the death-thought accessibility hypothesis. DTA is basically reversed MS; it states that if a particular aspect of a subject's cultural worldview is attacked or threatened, it will cause thoughts of death to be unconsciously more prevalent in the mind of the subject. In one study performed at the University of Alberta, Schimel, Hayes, Williams, and Jahrig (2007) led subjects to a webpage that either derogated Canadian or Australian values. DTA was then measured using a word fragment completion task and a lexical decision task as described in detail by Schimel et al., (2007). After reading the webpage that threatened the Canadian values, the subjects showed a greater accessibility for death-related words. The researchers also tested to see if the same results were found if generally negative words, rather than specifically death-related words, were tested for. Interestingly, there was no difference in the results for the negative words control and the neutral words control. This shows that attacking the subject's cultural worldview increases the accessibility of death thoughts only, and doesn't just put the subject in a negative state of mind.

As a final point of interest, another study conducted at the University of Alberta (Schimel, Hayes, Williams, 2007) tested whether the annihilation of those who threaten a subject's cultural worldview could have a buffering effect on DTA much like the bolstering of self-esteem has a buffering effect on MS. A sample of Christian subjects read either a nonworldview-threatening article about the aurora borealis, or worldview-threatening article on how the childhood home of Jesus Christ, Nazareth, is falling increasingly under Muslim control and influence. Half of the 
subjects in the worldview-threatening group, however, had an additional paragraph at the bottom of the article that informed them that a plane full of 117 Muslims on their way to Nazareth had crashed and that there were no survivors. The subjects then completed a word fragment completion task to assess the accessibility of death thoughts. The results showed that the threat group showed increased DTA, whereas the control and threat/annihilation groups showed little difference. In addition, the threat group rated their liking for Muslims and others (Jews, Hindus, Atheists) much lower than the control or annihilation groups. The study shows that the annihilation of those who threaten one's worldview can have a buffering effect on DTA, much like bolstered self-esteem can buffer the effects of MS. The lower rating for other religious groups in non-annihilation subjects shows a decreased opinion of those that differ from their cultural worldview when that worldview is threatened. This was not seen in the annihilation group because they no longer needed to defend their own worldview; learning of the death of members of an opposing worldview serves this function for them. While some may argue that the annihilation groups rated their liking for Muslims higher out of sympathy, this explanation does not address why they also increased their opinion of Jews, Atheists, and Hindus. This can only be explained by the buffering of death-related anxiety leading to the loss of especially negative reactions to culturally dissimilar persons.

This is by no means a comprehensive account of all the studies that have been done on this topic. Over 200 studies have been done in North America and overseas on Mortality Salience alone. This is simply a small account of some of the most convincing research that has been done, some of which at our own university. The principles of TMT have been tested extensively and are supported by a large volume of psychological study. Other cognitive-behavioural and evolutionary ways to describe the behaviours observed are addressed in many of the studies, and in many cases are not capable of explaining the results with the same certainty and clarity of TMT. These concrete studies as well as the profound theoretical insight based on sound clinical observation both serve to establish TMT as a comprehensive and reliable model for predicting social behaviour in human beings.

\section{CONCLUSION}

Terror management theory, while both refreshing and convincing, is fundamentally just that, a theory. Many in the field of psychoanalysis retain the belief that social factors such as development of the personality during childhood, repressed experiences and emotions, and sexual and aggressive instincts have a stronger role in development. This bivalency can be described in terms of the familiar debate of nature vs. nurture. In this per- spective, TMT argues in the favour of the importance of a person's existential nature, stating that aspects of behaviour originate from a common intrinsic dilemma for all people, and childhood development serves to differentiate how people deal with this dilemma using the complex social structures available to them.

Terror management theory is a look into the human experience that looks beyond the specifics of neuroscience and the simplicity of previous behavioural studies, and attempts to form an intelligent general theory for the shared life experience of all human beings. It looks into the deepest and most fundamental essence of humanity and attempts to explain with a holistic perspective the central motivations behind our instinctive actions, our most profound thoughts, and our innermost emotions. Through the examples of transference, heroism and religion, I have attempted to explain some of these behaviours, only a small subset of the emotions, behaviours and disorders that TMT can elaborate on, and the complexities that lead to their development.

TMT is also the first psychoanalytic theory to be supported by scientific experiment. Hundreds of studies in the past few decades have provided convincing evidence, and research has only but begun in this promising new psychological perspective. Further research in this field will allow psychologists to answer not just how behaviours develop, as is the focus in psychology at the present, but why they develop. This perspective is crucial because it will allow humanity to understand from a common viewpoint our most unsettling behaviours, and thereby allow us to address of the vast quantities of negative emotion and hurtful behaviour that is present in the world. Once we, as a species, can realise that evil, as well as good is simply a necessary product of our nature as human beings, only then can we intelligently self-regulate our hateful and aggressive emotions, sober, and without shame. Only then can we choose worldviews and paths in life that are not so insecure that they will eventually lead to psychological distress. Only if we can understand the science of evil, do we stand the chance of abolishing it.

\section{REFERENCES}

Arndt J, Cook A, Greenberg J, Landau MJ, Miller D, Ogilvie D, Solomon S. (2004). Deliver us from evil: The effects of mortality salience and reminders of $9 / 11$ on support for president George W. Bush. Personality and Social Psychology Bulletin, 30(9), 1136-1150.

Becker E. (1973). The Denial of Death. New York, NY: The Free Press.

Greenberg J. (2008) Understanding the vital human quest for self-esteem. Perspectives on Psychological Science, 3(1).

Greenberg J, Harmon-Jones E, McGregor H, Pyszczynski T, Simon L, Solomon S. (1997). Terror management theory and self-esteem: Evidence that increased self- 
esteem reduces mortality salience effects. Journal of Personality and Social Psychology, 72(1), 24-36.

Greenberg J, Kirkland S, Lyon D, Pyszczynski T, Rosenblatt A, Solomon S, Veeder M. (1990). Evidence for terror management theory II: The effects of mortality salience on reactions to those who threaten or bolster the cultural worldview. Journal of Personality and Social Psychology, 58(2), 308-318.

Greenberg J, Lyon D, Pyszczynski T, Rosenblatt A, Solomon S. (1989). Evidence for terror management theory: I. the effects of mortality salience on reactions to those who violate or uphold cultural values. Journal of Personality and Social Psychology, 57(4), 681-690.

Hayes J, Jahrig. J., Schimel J, Williams T. (2007). Is death really the worm at the core? Converging evidence that worldview threat increases death-thought accessibility. Journal of Personality and Social Psychology, 92(5), 789-803.

Hayes J, Schimel J, Williams T. (2007). Fighting death with death. The buffering effects of learning that worldview violators have died. Psychological Science, 19(5), 501-507.

Helzer JE, Robins LN, McEvoy L. (1987). Post-traumatic stress disorder in the general population. England Jour- nal of Medicine, 317(26), 1630-1634.

Internet Encyclopedia of Philosophy. (2010). Ancient Greek Philosophy. Retrieved from: http:/ / www.iep.utm.edu/greekphi/

Latham T. (n.d) The birth of psychoanalysis: Nietzsche's legacy and influence on Freudian thought document Research Paper. Psychology Today. Retrieved from http://www.psychologytoday.com/files/attachments/ 58144/the-birth-psychoanalysis.pdf

Mikulenka J. (Director). (2007). Hunting the zodiac [Documentary]. United States: John Mikulenka

Rossano JM. (2006) The religious mind and the evolution of religion. Review of General Psychology, 10(4), 346364.

Shen P. (Director). (2006). Flight from death: The quest for immortality. [Documentary]. United States: Patrick Shen, Greg Bennick

The 9/11 Commission. (2004). The 9/11 commission report. (United States National Commission on Terrorist Attacks Upon the United States). Washington, DC

The Pew Forum on Religion \& Public Life. (2011). World Muslim Population Data Tables. Retreived from: http:/ / features.pewforum.org/muslim-population/. 